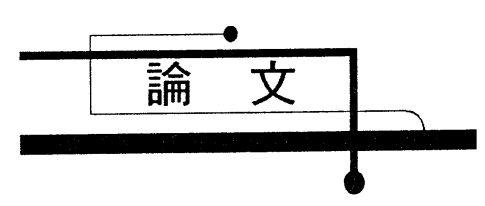

\title{
Numerical Analyses of Air Lift Pumps based on the Multi-Fluid Model
}

\author{
Akio TOMIYAMA ${ }^{* *}$ \\ Hisato MINAGAWA ${ }^{* *}$
}

\author{
Naoya FURUTANI ${ }^{\dagger}$
}

Tadashi SAKAGUCHI ${ }^{* *}$

\begin{abstract}
Air lift pumps are regarded as one of the useful means of conveying liquid or solid particles. Accurate methods for estimating pump performance are required to carry out rational design of the pumps. Although several numerical methods to predict the pump performance have been already proposed, none of them are based on the multi-fluid model. Hence, a numerical method based on the multi-fluid model for steady gas-liquid-solid three-phase flow was proposed and examined in the present study. Since it had not been clear if the multi-fluid model could be applied to air lift pumps,pumps for lifting liquid were analyzed by implementing well-known correlations of the two-fluid model into the present method. It was confirmed by comparisons between calculated and available experimental data that the present method can predict the pump performance accurately under a wide range of flow conditions. In other words, the validity of the present method and the adopted correlations was confirmed. Then, a pump to lift solid particles was analyzed. Since there are few available correlations for the three-fluid model, correlations adopted in the analysis were tentative ones. However the present method gave relatively good predictions.
\end{abstract}

Keywords : Air Lift Pump, Multi-Fluid Model, Three-Phase Flow, Numerical Analysis, Correlations

\section{INTRODUCTION}

Air lift pumps are regarded as one of the useful means to lift corrosive liquid such as radioactive waste of nuclear reprocessing plants and hot spring water, or to lift abrasive slurries and solid particles such as manganese nodules at deep sea beds. A number of studies have been therefore conducted to make characteristics of the air lift pumps clear. Many numerical methods have been also proposed to predict performance of lifting liquid or solid[1]-[13]. Mathematical models adopted

* Recieved 2.24.1992

** Faculty of Engineering, Kobe University. Rokkodai, Nada, Kobe 657, Japan

+ Graduate School of Kobe University. Rokkodai, Nada, Kobe 657, Japan 
for these methods can be classified into a lumped parameter model [1]-[9] and a distributed parameter model [10]-[13]. The former model treats the whole length of a lifting pipe as one control volume to which mass and momentum balances are applied, while the latter divides the lifting pipe into many small control volumes to predict axial variations of flow quantities in detail. Since precise knowledge on the characteristics of the pumps comes to be required at present, only the distributed parameter model which satisfies this requirement is considered in the present study .

In order to predict the lifting performance accurately, it is necessary to evaluate all components of total pressure drop in the lifting pipe. They consist of accelerational, frictional and gravitational pressure drops as well as singular pressure drop which depends on the structure of each air lift pump. However there seem to be few available methods which take into account all the components.

As for a mathematical model of the multiphase flow in the air lift pumps, available methods have adopted the slip model [1] [11], [13] or the drift-flux model[12]. That is, the multi-fluid model has not been applied to the air lift pumps yet. Since the slip and the drift-flux models assume strong coupling between different phases, they may not be appropriate for accelerating flows such as a flow in a long vertical air lift pipe or a transient flow encountered in starting or stopping of the pumps. The multi-fluid model is more preferable in this case because it treats each phase separately. On the other hand, many constitutive equations are required to close the multi-fluid model mathematically. These constitutive equations affect the accuracy of predictions. At present, it has not been made clear that available constitutive equations are of use to predict the performance of the air lift pumps.

Hence, as a preparation for transient analyses of the air lift pumps, a numerical method to predict steady state performance of the pumps, which is based on the multi-fluid model, was proposed and examined in the present study. The present method takes into account all components of the total pressure drop. Examinations were conducted for air lift pumps to convey liquid or solid particles under a wide range of flow condition.

\section{MULTI-FLUID MODEL AND ITS NUMERICAL SOLUTION METHOD \\ 2.1 Field and Constitutive Equations}

Field equations of the gas-liquid-solid three-phase flow and constitutive equations are summarized below. Assumptions adopted for modelling are as follows:

(1) The cross-sectional area of the pipe is constant.

(2) The flow is in steady-state.

(3) There is no phase change, and the temperature of the fluids and the solid is constant.

(4) Pressure is constant in the cross-sectional area of the pipe.

Under these assumptions, the area-averaged field equations [14],[15] are given by

$$
\begin{aligned}
& \left\langle\alpha_{G}\right\rangle+\left\langle\alpha_{L}\right\rangle+\left\langle\alpha_{S}\right\rangle=1, \\
& \left\langle G_{G}\right\rangle=\rho_{G}\left\langle\alpha_{G}\right\rangle \overline{V_{G}}=\text { const., } \\
& \left\langle G_{L}\right\rangle=\rho_{L}\left\langle\alpha_{L}\right\rangle \overline{V_{L}}=\text { const., } \\
& \left\langle G_{S}\right\rangle=\rho_{S}\left\langle\alpha_{S}\right\rangle \overline{V_{S}}=\text { const., }
\end{aligned}
$$




$$
\begin{aligned}
& \left\langle G_{\mathrm{G}}\right\rangle \mathrm{d} \bar{V}_{\mathrm{G}} / \mathrm{d} z+\left\langle\alpha_{\mathrm{G}}\right\rangle \mathrm{d} \bar{P} / \mathrm{d} z \\
& =-\left\langle M_{\mathrm{GL}}\right\rangle-\left\langle M_{\mathrm{GS}}\right\rangle-\left\langle F_{\mathrm{G}}\right\rangle-\left\langle\alpha_{\mathrm{G}}\right\rangle \rho_{\mathrm{G}} g,
\end{aligned}
$$

$\left\langle G_{\mathrm{L}}\right\rangle \mathrm{d} \overline{V_{\mathrm{L}}} / \mathrm{d} z+\left\langle\alpha_{\mathrm{L}}\right\rangle \mathrm{d} \bar{P} / \mathrm{d} z$

$=+\left\langle M_{\mathrm{GL}}\right\rangle-\left\langle M_{\mathrm{LS}}\right\rangle-\left\langle F_{\mathrm{L}}\right\rangle-\left\langle\alpha_{\mathrm{L}}\right\rangle \rho_{\mathrm{L}} g$,

$\left\langle G_{\mathrm{S}}\right\rangle \mathrm{d} \overline{V_{\mathrm{S}}} / \mathrm{d} z+\left\langle\alpha_{\mathrm{s}}\right\rangle \mathrm{d} \bar{P} / \mathrm{d} z$

$=+\left\langle M_{\mathrm{GS}}\right\rangle+\left\langle M_{\mathrm{LS}}\right\rangle-\left\langle F_{\mathrm{S}}\right\rangle-\left\langle\alpha_{\mathrm{s}}\right\rangle \rho_{\mathrm{S}} g$,

where the symbols, $\langle\mathrm{x}\rangle$ and $\overline{Y_{\mathrm{n}}}$, denote the area-averaging for the quantity $x$ and the $\mathrm{n}$-phase averaging for the $\mathrm{n}$-phase quantity $Y_{\mathrm{n}}$, which are defined by

$$
\begin{aligned}
& \langle x\rangle=\frac{1}{A} \int_{A} x \mathrm{~d} A, \\
& \overline{Y_{\mathrm{n}}}=\left\langle\alpha_{\mathrm{n}} Y_{\mathrm{n}}\right\rangle\left\langle\left\langle\alpha_{\mathrm{n}}\right\rangle .\right.
\end{aligned}
$$

The area-averaged momentum diffusion $\left\langle F_{\mathrm{n}}\right\rangle$ in Eqs. (5)-(7) represents wall friction caused by the $n$-phase. Since we have assumed the steady flow, all the local quantities appearing in Eqs. (1)-(7) are considered to have been time-averaged with a time-scale enough to define the local volumetric fractions, $\alpha_{\mathrm{n}}$.

We must provide equations of state and constitutive equations in order to close Eqs. (1) - (7) mathematically. From the assumption (3), the densities of the liquid and the gas phases can be expressed in terms of pressure while that of the solid phase is constant. Hence, the equations of state are expressed by

$$
\begin{aligned}
& \rho_{\mathrm{G}}=\rho_{\mathrm{G}}(\bar{P}), \\
& \rho_{\mathrm{L}}=\rho_{\mathrm{L}}(\bar{P}), \\
& \rho_{\mathrm{S}}=\text { const. } .
\end{aligned}
$$

As for the interfacial momentum transfer, $\left\langle M_{\mathrm{ij}}\right\rangle$, between the lighter phase ' $\mathrm{i}$ ' and the heavier phase ' $\mathrm{j}$ ', it is usually expressed by the sum of the interfacial drag force $\left\langle M_{\mathrm{Dij}}\right\rangle$ and the virtual mass force $\left\langle M_{\mathrm{Vij}}\right\rangle$ :

$$
\left\langle M_{\mathrm{ij}}\right\rangle=\left\langle M_{\mathrm{Dij}}\right\rangle+\left\langle M_{\mathrm{vij}}\right\rangle .
$$

Since there were no available constitutive equations for $\left\langle M_{\mathrm{Dij}}\right\rangle$ of the three-phase flow, the authors[16],[17] have quite recently proposed a model for $\left\langle M_{\mathrm{Dij}}\right\rangle$ which takes into account an effect of the distributions of the local volumetric fractions and the local velocities in the cross-section of the pipe. This model is expressed by

$$
\left\langle M_{\mathrm{Dij}}\right\rangle=K_{\mathrm{ij}}\left(\overline{V_{\mathrm{i}}}-\overline{V_{\mathrm{j}}}\right),
$$

where

$$
\begin{aligned}
K_{\mathrm{ij}} & =\left(\frac{\left\langle\alpha_{i}\right\rangle\left\langle\alpha_{j}\right\rangle\left(\rho_{j}-\rho_{i}\right) g}{V_{\mathrm{Rij}}\left|V_{\mathrm{Rij}}\right|}\right. \\
& \left.-\frac{\left\langle\alpha_{j}\right\rangle\left\langle F_{i}\right\rangle+\left\langle\alpha_{i}\right\rangle\left\langle F_{j}\right\rangle}{V_{\mathrm{Rij}}\left|V_{\mathrm{Rij}}\right|}\right) \\
& \times\left|\overline{V_{\mathrm{i}}}-\overline{V_{\mathrm{j}}}\right| .
\end{aligned}
$$

Here $K_{\mathrm{ij}}$ corresponds to a physical parameter defined by

$$
K_{\mathrm{ij}}=\frac{1}{8} a_{\mathrm{ij}} C_{\mathrm{Dij}} \rho_{\mathrm{c}}\left|V_{\mathrm{i}}-V_{\mathrm{j}}\right|
$$

where $a_{\mathrm{ij}}$ denotes the interfacial area per unit volume, $C_{\mathrm{Dij}}$ the interfacial drag coefficient and $\rho_{\mathrm{C}}$ the density of the continuous phase among the phases $\mathrm{i}$ and $\mathrm{j}$. The term, $V_{\text {Rij }}$, is the relative velocity expressed in terms of a drift velocity and a distribution parameter. When the liquid is a continuous phase and the densities satisfy $\rho_{\mathrm{S}}>\rho_{\mathrm{L}}>\rho_{\mathrm{G}}$, the relative velocities are given by

$$
\begin{aligned}
V_{\mathrm{RLS}} & =\left(\left\langle\alpha_{\mathrm{L}}\right\rangle+\left\langle\alpha_{\mathrm{S}}\right\rangle\right) \\
& \times \frac{\left(1-C_{\mathrm{S}, \mathrm{G}}\right) \bar{V}_{L}+\bar{V}_{\mathrm{SJ}, \mathrm{G}}}{\left\langle\alpha_{\mathrm{L}}\right\rangle+\left\langle\alpha_{\mathrm{S}}\right\rangle-C_{\mathrm{S}, \mathrm{G}}\left\langle\alpha_{\mathrm{S}}\right\rangle},
\end{aligned}
$$




$$
\begin{aligned}
V_{\mathrm{RGL}} & =\left(\left\langle\alpha_{\mathrm{G}}\right\rangle+\left\langle\alpha_{\mathrm{L}}\right\rangle\right) \\
& \times \frac{\left(C_{\mathrm{G}, \mathrm{S}}-1\right) \bar{V}_{\mathrm{L}}+\bar{V}_{\mathrm{GJ}, \mathrm{S}}}{\left\langle\alpha_{\mathrm{G}}\right\rangle+\left\langle\alpha_{\mathrm{L}}\right\rangle-C_{\mathrm{G}, \mathrm{S}}\left\langle\alpha_{\mathrm{G}}\right\rangle}, \\
V_{\mathrm{RGS}} & =\left(\left\langle\alpha_{\mathrm{G}}\right\rangle+\left\langle\alpha_{\mathrm{S}}\right\rangle\right) \\
& \times \frac{\left(1-C_{\mathrm{S}, \mathrm{L}}\right) \bar{V}_{\mathrm{G}}+\bar{V}_{\mathrm{SJ}, \mathrm{L}}}{\left\langle\alpha_{\mathrm{G}}\right\rangle+\left\langle\alpha_{\mathrm{S}}\right\rangle-C_{\mathrm{S}, \mathrm{L}}\left\langle\alpha_{\mathrm{S}}\right\rangle} .
\end{aligned}
$$

Here $C_{\mathrm{i}, \mathbf{k}}$ is the distribution parameter of the $\mathrm{i}$-phase in a hypothetical two-phase flow which is conceived by removing the $\mathrm{k}$-phase from the three-phase flow consisting of the $\mathrm{i}, \mathrm{j}$ and $\mathrm{k}$ phases[16],[17]. The term, $\overline{V_{\mathrm{iJ}, \mathrm{k}}}$, is the phase averaged drift velocity of the $\mathrm{i}$-phase in the hypothetical two-phase flow. By substituting experimental or semi-empirical correlations into $C_{\mathrm{i}, \mathrm{k}}$ and $\overline{V_{\mathrm{iJ}, \mathrm{k}}}$, we can evaluate $\left\langle M_{\mathrm{Dij}}\right\rangle$. It should be noted that Eqs. (14)-(19) can be applied even to two-phase flow. In this case, we can make use of existing correlations of the distribution parameter and the drift velocity of the two-phase flow to evaluate $C_{\mathrm{i}, \mathrm{k}}$ and $V_{\mathrm{ij}, \mathrm{k}}$.

A reliable model for the virtual mass force has not been proposed even for the two-phase flow. In this study, we applied Drew's model[18] of the virtual mass force for the two-phase flow to the hypothetical two-phase flow. The model is expressed by

$$
\begin{aligned}
& \left\langle M_{\mathrm{vij}}\right\rangle=\xi_{\mathrm{ij}} \frac{\mathrm{d} \overline{V_{\mathrm{i}}}}{\mathrm{d} z}+\eta_{\mathrm{ij}} \frac{\mathrm{d} \overline{V_{\mathrm{j}}}}{\mathrm{d} z}, \\
& \xi_{\mathrm{ij}}=\frac{\left\langle\alpha_{\mathrm{i}}\right\rangle \tilde{\rho}_{\mathrm{ij}} C_{\mathrm{v}_{\mathrm{ij}}}\left[\overline{V_{\mathrm{i}}}-\left(\kappa_{\mathrm{ij}}-2\right)\left(\overline{V_{\mathrm{i}}}-V_{\mathrm{j}}\right)\right]}{\left\langle\alpha_{\mathrm{i}}\right\rangle+\left\langle\alpha_{\mathrm{j}}\right\rangle}, \\
& \xi_{\mathrm{ij}}=\frac{\left\langle\alpha_{\mathrm{j}}\right\rangle \tilde{\rho}_{\mathrm{ij}} C_{\mathrm{vij}_{\mathrm{ij}}}\left[-\overline{V_{\mathrm{i}}}+\left(1-\kappa_{\mathrm{ij}}\right)\left(\overline{V_{\mathrm{i}}}-V_{\mathrm{j}}\right)\right]}{\left\langle\alpha_{\mathrm{i}}\right\rangle+\left\langle\alpha_{\mathrm{j}}\right\rangle},
\end{aligned}
$$

where the subscript $i$ denotes the dispersed phase and $j$ the continuous phase, $\tilde{\rho}_{i j}$ the density of the fluid surrounding a dispersed bubble, drop or particle, $C_{\mathrm{V}_{\mathrm{ij}}}$ the virtual mass coefficient and $\kappa_{\mathrm{ij}}$ the parameter regarding the acceleration due to the virtual mass force. Correlations for $\tilde{\rho}_{\mathrm{ij}}, C_{\mathrm{Vij}}$ and $\boldsymbol{\kappa}_{\mathrm{ij}}$ are required to close this virtual mass model.

The sum of the wall friction of each phase is equal to the frictional pressure gradient of the three phase flow, $(\mathrm{d} \bar{P} / d z)_{\mathrm{f}}$. Hence we can evaluate $\left\langle F_{\mathrm{n}}\right\rangle$ by dividing ( $\overline{\mathrm{d}} \bar{P}$ / $\mathrm{dz})_{\mathrm{f}}$ among $\left\langle F_{\mathrm{G}}\right\rangle,\left\langle F_{\mathrm{L}}\right\rangle$ and $\left\langle F_{\mathrm{S}}\right\rangle$ as follows:

$$
\begin{aligned}
& \left\langle F_{\mathrm{G}}\right\rangle=\omega_{\mathrm{G}}\left(\frac{\mathrm{d} \bar{P}}{\mathrm{~d} z}\right)_{f}, \\
& \left\langle F_{\mathrm{L}}\right\rangle=\omega_{\mathrm{L}}\left(\frac{\mathrm{d} \bar{P}}{\mathrm{~d} z}\right)_{f}, \\
& \left\langle F_{\mathrm{S}}\right\rangle=\omega_{\mathrm{s}}\left(\frac{\mathrm{d} \bar{P}}{\mathrm{~d} z}\right)_{f},
\end{aligned}
$$

where $\omega_{n}$ is a parameter which satisfies

$$
\omega_{\mathrm{G}}+\omega_{\mathrm{L}}+\omega_{\mathrm{S}}=1 \text {. }
$$

\subsection{Numerical Method}

By differentiating Eqs. (1)-(4), (10) and (11) with respect to $z$, we obtain

$$
\frac{\mathrm{d}\left\langle\alpha_{\mathrm{G}}\right\rangle}{\mathrm{d} z}+\frac{\mathrm{d}\left\langle\alpha_{\mathrm{L}}\right\rangle}{\mathrm{d} z}+\frac{\mathrm{d}\left\langle\alpha_{\mathrm{s}}\right\rangle}{\mathrm{d} z}=0,
$$

$$
\begin{aligned}
& \rho_{\mathrm{G}}\left\langle\alpha_{\mathrm{G}}\right\rangle \frac{\mathrm{d} \overline{V_{\mathrm{G}}}}{\mathrm{d} z}+\rho_{\mathrm{G}} \overline{V_{\mathrm{G}}} \frac{\mathrm{d}\left\langle\alpha_{\mathrm{G}}\right\rangle}{\mathrm{d} z} \\
&+\left\langle\alpha_{\mathrm{G}}\right\rangle \bar{V}_{\mathrm{G}} \frac{\mathrm{d} \rho_{\mathrm{G}}}{\mathrm{d} z}=0, \\
& \rho_{\mathrm{L}}\left\langle\alpha_{\mathrm{L}}\right\rangle \frac{\mathrm{d} \overline{V_{\mathrm{L}}}}{\mathrm{d} z}+\rho_{\mathrm{L}} \overline{V_{\mathrm{L}}} \frac{\mathrm{d}\left\langle\alpha_{\mathrm{L}}\right\rangle}{\mathrm{d} z} \\
&+\left\langle\alpha_{\mathrm{L}}\right\rangle \overline{V_{\mathrm{L}}} \frac{\mathrm{d} \rho_{\mathrm{L}}}{\mathrm{d} z}=0,
\end{aligned}
$$




$$
\begin{aligned}
& \rho_{\mathrm{S}}\left\langle\alpha_{\mathrm{s}}\right\rangle \frac{\mathrm{d} \overline{V_{\mathrm{s}}}}{\mathrm{d} z}+\rho_{\mathrm{s}} \overline{V_{\mathrm{s}}} \frac{\mathrm{d}\left\langle\alpha_{\mathrm{s}}\right\rangle}{\mathrm{d} z}=0, \\
& \frac{\mathrm{d} \rho_{\mathrm{G}}}{\mathrm{d} z}-\frac{\mathrm{d} \rho_{\mathrm{G}}}{\mathrm{d} \bar{P}} \frac{\mathrm{d} \bar{P}}{\mathrm{~d} z}=0 \\
& \frac{\mathrm{d} \rho_{\mathrm{L}}}{\mathrm{d} z}-\frac{\mathrm{d} \rho_{\mathrm{L}}}{\mathrm{d} \bar{P}} \frac{\mathrm{d} \bar{P}}{\mathrm{~d} z}=0
\end{aligned}
$$

Then, substituting Eqs. (13) and (20) into Eqs. (5)-(7) yields

$$
\begin{aligned}
& \left(\left\langle G_{\mathrm{G}}\right\rangle+\xi_{\mathrm{GL}}+\xi_{\mathrm{GS}}\right) \frac{\mathrm{d} \overline{V_{\mathrm{G}}}}{\mathrm{d} z}+\eta_{\mathrm{GL}} \frac{\mathrm{d} \overline{V_{\mathrm{L}}}}{\mathrm{d} z} \\
& +\eta_{\mathrm{GS}} \frac{\mathrm{d} \bar{V}_{\mathrm{S}}}{\mathrm{d} z}+\left\langle\alpha_{\mathrm{G}}\right\rangle \frac{\mathrm{d} \bar{P}}{\mathrm{~d} z}=B_{\mathrm{G}} \\
& -\xi_{\mathrm{GL}} \frac{\mathrm{d} \bar{V}_{\mathrm{G}}}{\mathrm{d} z}+\left(\left\langle G_{\mathrm{L}}\right\rangle-\eta_{\mathrm{GL}}+\eta_{\mathrm{SL}}\right) \frac{\mathrm{d} \bar{V}_{\mathrm{L}}}{\mathrm{d} z} \\
& +\xi_{\mathrm{SL}} \frac{\mathrm{d} \overline{V_{\mathrm{S}}}}{\mathrm{d} z}+\left\langle\alpha_{\mathrm{S}}\right\rangle \frac{\mathrm{d} \bar{P}}{\mathrm{~d} z}=B_{\mathrm{L}} \\
& -\xi_{\mathrm{GS}} \frac{\mathrm{d} \overline{V_{\mathrm{G}}}}{\mathrm{d} z}-\eta_{\mathrm{SL}} \frac{\mathrm{d} \overline{V_{\mathrm{L}}}}{\mathrm{d} z} \\
& +\left(\left\langle G_{\mathrm{S}}\right\rangle-\xi_{\mathrm{SL}}-\eta_{\mathrm{GS}}\right) \frac{\mathrm{d} \overline{V_{\mathrm{S}}}}{\mathrm{d} z} \\
& +\left\langle\alpha_{\mathrm{S}}\right\rangle \frac{\mathrm{d} \bar{P}}{d z}=B_{\mathrm{S}}
\end{aligned}
$$

where

$$
\begin{aligned}
B_{\mathrm{G}}= & -\left\langle M_{\mathrm{DGL}}\right\rangle-\left\langle M_{\mathrm{DGS}}\right\rangle \\
& -\left\langle F_{\mathrm{G}}\right\rangle-\left\langle\alpha_{\mathrm{G}}\right\rangle \rho_{\mathrm{G}} g, \\
B_{\mathrm{L}}= & +\left\langle M_{\mathrm{DGL}}\right\rangle-\left\langle M_{\mathrm{DLS}}\right\rangle \\
& -\left\langle F_{\mathrm{L}}\right\rangle-\left\langle\alpha_{\mathrm{L}}\right\rangle \rho_{\mathrm{L}} g, \\
B_{\mathrm{S}}= & +\left\langle M_{\mathrm{DGS}}\right\rangle+\left\langle M_{\mathrm{DLS}}\right\rangle \\
& -\left\langle F_{\mathrm{S}}\right\rangle-\left\langle\alpha_{\mathrm{S}}\right\rangle \rho_{\mathrm{S}} g .
\end{aligned}
$$

Equations (25)-(33) can be therefore rewritten as a following vector differential equation:

$$
\mathrm{d} \mathbf{X} / \mathrm{d} z=\mathbf{f}(\mathbf{X}),
$$

where $\mathbf{X}$ denotes the column vector of the dependent variables :

$$
\begin{aligned}
\mathrm{X}= & \left(\left\langle\alpha_{\mathrm{G}}\right\rangle,\left\langle\alpha_{\mathrm{L}}\right\rangle,\left\langle\alpha_{\mathrm{S}}\right\rangle, \overline{V_{\mathrm{G}}}, \overline{V_{\mathrm{L}}}, \overline{V_{\mathrm{S}}},\right. \\
& \left.\rho_{\mathrm{G}}, \quad \rho_{\mathrm{L}}, \bar{P}\right)^{t},
\end{aligned}
$$

and $\mathbf{f}(\mathbf{X})$ is also the column vector whose elements are a function of the elements of $\mathbf{X}$. Hence, if the value of $\mathbf{X}$ is given at a certain location $z_{0}$, we can integrate Eq.(37) with respect to $z$ using numerical methods such as the Runge-Kutta method to obtain a solution vector $\mathbf{X}(\mathbf{z}), \mathbf{z} \geqq z_{0}$. However, in order to conduct calculations, we must specify the equations of state, $\rho_{\mathrm{G}}(\overline{\mathrm{P}})$ and $\rho_{\mathrm{L}}(\overline{\mathrm{P}})$, and correlations for $C_{\mathrm{S}, \mathrm{G}}, C_{\mathrm{G}, \mathrm{S}}, C_{\mathrm{S}, \mathrm{L}}, \overline{V_{\mathrm{SJ}, \mathrm{G}}}$, $\overline{V_{\mathrm{GJ}, \mathrm{S}}}, \overline{V_{\mathrm{SJ}} \mathrm{L}}, \quad \tilde{\rho}_{\mathrm{GL}}, \quad \tilde{\rho}_{\mathrm{GS}}, \tilde{\rho}_{\mathrm{LS}}, C_{\mathrm{VGL}}, C_{\mathrm{VGS}}$, $C_{\mathrm{VLS}}, \kappa_{\mathrm{GL}}, \kappa_{\mathrm{GS}}, \kappa_{\mathrm{LS}}, \omega_{\mathrm{G}}, \omega_{\mathrm{L}}, \omega_{\mathrm{S}}$, and $(\mathrm{d} \bar{P} / d z)_{\mathrm{f}}$.

\section{NUMERICAL METHOD FOR AIR \\ LIFT PUMP ANALYSES}

A schematic of a typical air lift pump for lifting solid particles is shown in Fig. 1 together with a pressure distribution along the flow direction. As shown in this figure, the vertical pipe used in the pump usually consists of three parts:

(1) a suction part where a solid-liquid mixture flows(length $L_{\mathrm{I}}$ ),

(2) a submerged part where a gas-liquidsolid mixture flows(length $L_{\mathrm{S}}$ ),

(3) a delivery or lifting part where a gas-liquid-solid mixture flows above the water-level (length $L_{\mathrm{D}}$ ).

By feeding compressed air through a mixing section, the static pressure inside the pipe becomes smaller than the one outside the pipe at the same axial location. This pressure difference induces an upward flow in the pipe. Some structures such as a horizontal straight pipe and a bend are often installed at the exit of the pipe. 


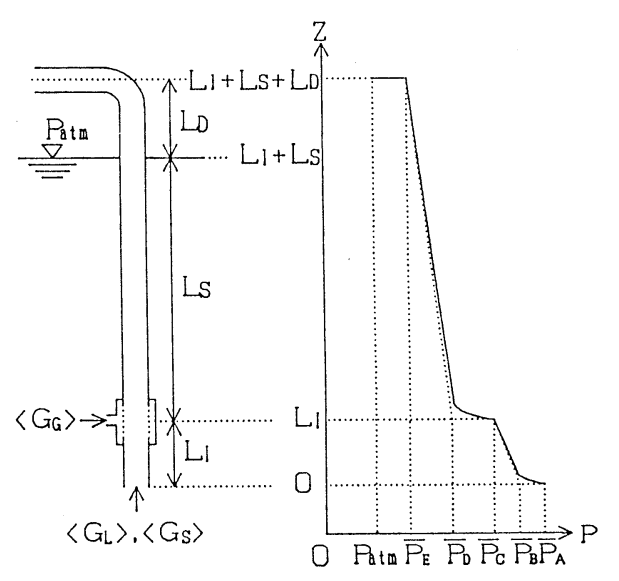

Fig. 1 A schematic of an air lift pump and its pressure distribution.

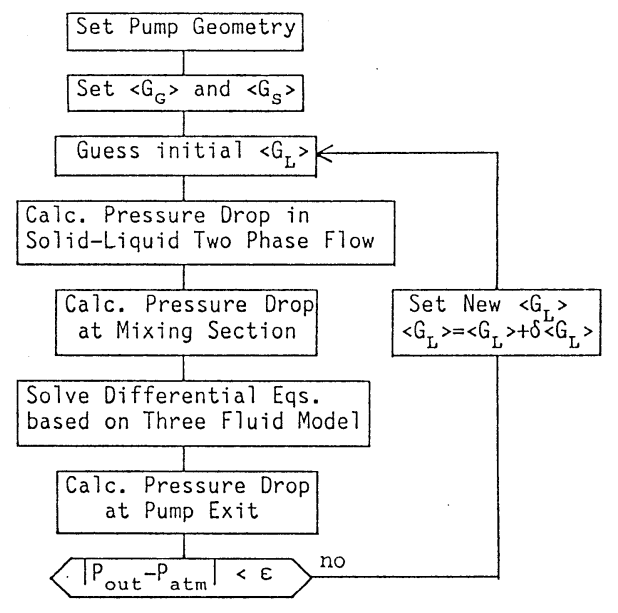

Fig. 2 Outline of the analyses.

The outline of the present method is shown in Fig. 2. Similar to usual methods [10]-[13], this method adopts the shooting method for the solution of a two-point boundary value problem specified by fixed pressures at the inlet and the outlet of the pipe. Under given mass fluxes of the gas and the solid phases, $\left\langle G_{\mathrm{G}}\right\rangle$ and $\left\langle G_{\mathrm{S}}\right\rangle$, this method predicts the liquid mass flux $\left\langle G_{\mathrm{L}}\right\rangle$ and the axial distributions of physical quantities.

Geometry of the pump, the mass fluxes $\left\langle G_{\mathrm{G}}\right\rangle$ and $\left\langle G_{\mathrm{S}}\right\rangle$, and the temperature of the fluids, $\mathrm{T}$, are given first. Then, a coarse estimation of $\left\langle G_{\mathrm{L}}\right\rangle$ is carried out using one of the available lumped parameter models [1]-[9]. The estimated $\left\langle G_{\mathrm{L}}\right\rangle$ is used as the initial guess.

The static pressure, $\overline{P_{\mathrm{A}}}$, at the inlet is obtained by integrating the following equation numerically:

$$
\overline{P_{\mathrm{A}}}=P_{\mathrm{atm}}+\int_{0}^{L_{\mathrm{t}}+L_{\mathrm{B}}} \rho_{\mathrm{L}} g d z .
$$

If $\rho_{\mathrm{L}}$ is constant, this equation reduces to a simple one; $\overline{P_{\mathrm{A}}}=P_{\mathrm{atm}}+\rho_{\mathrm{L}} g\left(L_{\mathrm{I}}+L_{\mathrm{S}}\right)$. The singular pressure drop at the inlet, $\Delta P_{\text {in }}$, can be expressed in terms of a pressure drop coefficient of an inlet fitting, $\zeta_{\text {in }}$, as follows:

$$
\Delta P_{\text {in }}=\zeta_{\text {in }} \rho_{\mathrm{L}}\left(\left\langle J_{\mathrm{L}}\right\rangle+\left\langle J_{\mathrm{S}}\right\rangle\right)^{2} / 2,
$$

where the area-averaged volumetric flux, $\left\langle J_{n}\right\rangle$, is defined by

$$
\left\langle J_{\mathrm{n}}\right\rangle=\left\langle G_{\mathrm{n}}\right\rangle / \rho_{\mathrm{n}} .
$$

In the entrance region, velocity profile in the cross-sectional area changes along the flow direction. This change produces the singular pressure drop, $\Delta P_{\mathrm{e}}[13]$. This pressure drop can be also expressed in terms of a pressure drop coefficient of the entrance region, $\zeta_{\mathrm{e}}$ :

$$
\Delta P_{\mathrm{e}}=\zeta_{\mathrm{e}} \rho_{\mathrm{L}}\left(\left\langle J_{\mathrm{L}}\right\rangle+\left\langle J_{\mathrm{s}}\right\rangle\right)^{2} / 2 .
$$

The pressure at the inside of the inlet, $\overline{P_{\mathrm{B}}}$, is therefore given by

$$
\overline{P_{\mathrm{B}}}=\overline{P_{\mathrm{A}}}-\Delta P_{\text {in }}-\Delta P_{\mathrm{e}} .
$$

As mentioned above, we have already taken into account the pressure drop to accelerate the solid-liquid two-phase flow at the inlet of the pump. Thus, if $\rho_{\mathrm{L}}$ is constant, no additional accelerational pressure drop is generated in the suction part. The length of 
this part is usually small compared with the total length of the pipe. Hence, the pressure drop in this part can be assumed not so large enough to change $\rho_{\mathrm{L}}$. It is therefore assumed that there is no additional accelerational pressure drop in the suction part, and that the solid-liquid two-phase flow is fully developed in this part. Under these assumptions, Eqs. (1)-(7) reduce to the follo wing equations:

$$
\begin{aligned}
&\left\langle\alpha_{\mathrm{L}}\right\rangle+\left\langle\alpha_{\mathrm{S}}\right\rangle=1, \\
&\left\langle G_{\mathrm{L}}\right\rangle=\rho_{\mathrm{L}}\left\langle\alpha_{\mathrm{L}}\right\rangle \overline{V_{\mathrm{L}}}=\text { const. } \\
&\left\langle G_{\mathrm{S}}\right\rangle=\rho_{\mathrm{S}}\left\langle\alpha_{\mathrm{S}}\right\rangle \overline{V_{\mathrm{S}}}=\text { const. } \\
&\left\langle\alpha_{\mathrm{L}}\right\rangle \mathrm{d} \bar{P} / \mathrm{d} z=-\left\langle M_{\mathrm{DLS}}\right\rangle-\left\langle F_{\mathrm{L}}\right\rangle \\
&-\left\langle\alpha_{\mathrm{L}}\right\rangle \rho_{\mathrm{L}} g, \\
&\left\langle\alpha_{\mathrm{S}}\right\rangle \mathrm{d} \bar{P} / \mathrm{d} z=+\left\langle M_{\mathrm{DLS}}\right\rangle-\left\langle F_{\mathrm{S}}\right\rangle \\
&-\left\langle\alpha_{\mathrm{S}}\right\rangle \rho_{\mathrm{S}} g .
\end{aligned}
$$

Equations (47) and (48) do not include the virtual mass force because no acceleration is assumed. As for the constitutive equations for $\left\langle M_{\mathrm{DLS}}\right\rangle,\left\langle F_{\mathrm{L}}\right\rangle$ and $\left\langle F_{\mathrm{S}}\right\rangle$, we can use Eqs. (14), (15), (17) and (23). Provided that correlations for $C_{\mathrm{S}}, \overline{V_{\mathrm{SJ}}}$ in Eq. (17) and $(\mathrm{d} \bar{P} /$ $\mathrm{dz})_{\mathrm{f}}$ in Eq. (23) are specified, Eqs. (44)-(48), (14), (15), (17) and (23) constitute a closed set of nonlinear simultaneous equations.

Dependent variables of the equation set are $\left\langle\alpha_{\mathrm{l}}\right\rangle,\left\langle\alpha_{\mathrm{S}}\right\rangle, \overline{V_{\mathrm{L}}}, \overline{V_{\mathrm{S}}}$ and $\mathrm{d} \bar{P} / \mathrm{dz}$. The simultaneous equations can be solved easily by the Newton-Raphson method as reported in Refs. [17],[19]. Hence the static pressure at the upstream-side of the mixing section, $\overline{P_{\mathrm{C}}}$, is given by

$$
\overline{P_{\mathrm{C}}}=\overline{P_{\mathrm{B}}}+(\mathrm{d} \bar{P} / \mathrm{d} z) L_{\mathrm{I}},
$$

where $d \bar{P} / \mathrm{dz}$ is the solution of Eqs. (44)-(48).

The singular pressure drop at the mixing section, $\Delta P_{\text {mix }}$, consists of two components. One is caused by a disturbance generated by air injection, the other accounts for the pressure drop required to develop the velocity distribution in the cross-section of the pipe. Referring to a model proposed by Yoshinaga, et al.[13], $\Delta P_{\operatorname{mix}}$ is approximated by the following equation:

$$
\begin{aligned}
& \Delta P_{\operatorname{mix}}= \\
& \frac{\zeta_{\mathrm{m}}}{2}\left[\left(\frac{\left\langle G_{\mathrm{G}}\right\rangle^{2}}{\rho_{\mathrm{G}}\left\langle\alpha_{\mathrm{G}}\right\rangle_{+}}+\frac{\left\langle G_{\mathrm{L}}\right\rangle^{2}}{\rho_{\mathrm{L}}\left\langle\alpha_{\mathrm{L}}\right\rangle_{+}}+\frac{\left\langle G_{\mathrm{S}}\right\rangle^{2}}{\rho_{\mathrm{S}}\left\langle\alpha_{\mathrm{S}}\right\rangle_{+}}\right)\right. \\
& \left.\quad-\left(\frac{\left\langle G_{\mathrm{L}}\right\rangle^{2}}{\rho_{\mathrm{L}}\left\langle\alpha_{\mathrm{L}}\right\rangle_{-}}+\frac{\left\langle G_{\mathrm{S}}\right\rangle^{2}}{\rho_{\mathrm{S}}\left\langle\alpha_{\mathrm{S}}\right\rangle_{-}}\right]\right)
\end{aligned}
$$

where $\zeta_{\mathrm{m}}$ is the pressure drop coefficient. The subscripts + and-denote the downstream side and the upstream side of the mixing section. The downstream volumetric fractions, $\left\langle\alpha_{n}\right\rangle_{+}$, are estimated by using correlations for the gas-liquid-solid three-phase flow $[17],[20],[21]$. For example, if a correlation proposed by the authors[17] is adopted, they can be evaluated by solving the following equations and Eq.(1) simultaneously:

$$
\begin{aligned}
& \frac{\left\langle J_{\mathrm{G}}\right\rangle}{\left\langle\alpha_{\mathrm{G}}\right\rangle_{+}}=C_{\mathrm{G}, \mathrm{S}} \frac{\left\langle J_{\mathrm{G}}\right\rangle+\left\langle J_{\mathrm{L}}\right\rangle}{1-\left\langle\alpha_{\mathrm{S}}\right\rangle_{+}}+\bar{V}_{\mathrm{G} J \mathrm{~S}}, \\
& \frac{\left\langle J_{\mathrm{S}}\right\rangle}{\left\langle\alpha_{\mathrm{S}}\right\rangle_{+}}=C_{\mathrm{S}, \mathrm{G}} \frac{\left\langle J_{\mathrm{S}}\right\rangle+\left\langle J_{\mathrm{L}}\right\rangle}{1-\left\langle\alpha_{\mathrm{G}}\right\rangle_{+}}+\bar{V}_{\mathrm{SJ}, \mathrm{G}} .
\end{aligned}
$$

By substituting appropriate correlations into $C_{\mathrm{G}, \mathrm{S}}, C_{\mathrm{S}, \mathrm{G}},{\overline{V_{\mathrm{GJ}} \mathrm{S}}}_{\mathrm{a}}$ and ${\overline{V_{\mathrm{SJ}}, \mathrm{G}}}_{\mathrm{G}}$, we can obtain $\left\langle\alpha_{\mathrm{n}}\right\rangle$ and $\overline{V_{\mathrm{n}}}$ at the downstream-side of the mixing section.

Then the static pressure at the downstream-side of the mixing section, $\overline{P_{\mathrm{D}}}$, is given by

$$
\overline{P_{\mathrm{D}}}=\overline{P_{c}}-\Delta P_{\operatorname{mix}} .
$$

This pressure is used as the initial condition 
for the numerical calculation of the gasliquid-solid three-phase flow based on the multi-fluid model. Then $\rho_{\mathrm{G}}$ and $\rho_{\mathrm{L}}$ are calculated by Eqs. (10) and (11) as $\rho_{\mathrm{G}}=\rho_{\mathrm{G}}$ $\left(\overline{P_{\mathrm{D}}}\right)$ and $\rho_{\mathrm{L}}=\rho_{\mathrm{L}}\left(\overline{P_{\mathrm{D}}}\right)$. These densities are used to calculate the volumetric flux of each phase by Eq. (41). The obtained $\left\langle J_{n}\right\rangle$ is substituted into Eqs. (51) and (52) to yield the initial conditions for $\left\langle\alpha_{n}\right\rangle$ and $\overline{V_{n}}$. Hence we can prepare the initial values for all the dependent variables in Eq. (38).

By integrating Eq. (37) from $\mathrm{z}=L_{\mathrm{I}}$ to $\mathrm{z}=L_{\mathrm{I}}+L_{\mathrm{S}}+L_{\mathrm{D}}$, we can obtain the static pressure at the exit of the pipe, $\overline{P_{\mathrm{E}}}$. Then we must evaluate the singular pressure drop at the exit of the pipe, $\Delta P_{\text {out }}$, with a certain correlation corresponding to the structure of the pipe exit. Finally, the static pressure at the outlet, $\bar{P}_{\text {out }}$, is given by

$$
\bar{P}_{\text {out }}=\overline{P_{\mathrm{E}}}-\Delta P_{\text {out }} \text {. }
$$

If the difference, $\left|P_{\mathrm{atm}}-\bar{P}_{\text {out }}\right|$, is greater than a convergence criteria $\varepsilon,\left\langle G_{\mathrm{L}}\right\rangle$ is modified to $\left\langle G_{\mathrm{L}}\right\rangle+\delta\left\langle G_{\mathrm{L}}\right\rangle$ and the whole procedure mentioned above is repeated again until the convergence is achieved. Efficiency of the shooting method is much affected by a method to determine increments of dependent variables. Since no systematic methods to determine $\delta\left\langle G_{\mathrm{L}}\right\rangle$ have been proposed yet, $\delta\left\langle G_{\mathrm{L}}\right\rangle$ has been determined by a trial and error method. In this study, a systematic method is developed by making use of a coarse approximation for the total pressure drop. The pressure difference between the inlet and the exit of

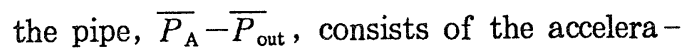
tional $\left(\Delta P_{\mathrm{ac}}\right)$, the gravitational $\left(\Delta P_{\mathrm{h}}\right)$, the frictional $\left(\Delta P_{\mathrm{f}}\right)$ and the singular pressure $\operatorname{drop}\left(\Delta P_{\mathrm{s}}\right)$. Therefore $\bar{P}_{A}-\bar{P}_{\text {out }}$ can be approximately given by

$$
\overline{P_{\mathrm{A}}}-\bar{P}_{\text {out }}=\Gamma \frac{\left\langle G_{\mathrm{L}}\right\rangle^{2}}{2 \rho_{\mathrm{L}}}+\Delta P_{\mathrm{ac}}+\Delta P_{\mathrm{h}}
$$

where $\Gamma$ is a constant which accounts for the pressure drop coefficients due to the wall friction and the singularity. Since $\rho_{\mathrm{G}}$ and $\left\langle\alpha_{\mathrm{S}}\right\rangle$ are usually small, kinematic energies of the gas and the solid phases have been neglected in the first term of the right-hand side of Eq. (55). Even if $\left\langle G_{\mathrm{L}}\right\rangle$ is changed slightly, $\Delta P_{\mathrm{ac}}$ and $\Delta P_{\mathrm{h}}$ will not change so much. Moreover, $\rho_{\mathrm{L}}$ can be postulated as a constant. A perturbed equation of Eq. (55) is therefore given by

$$
-\delta \overline{P_{\text {out }}}=\Gamma\left\langle G_{\mathrm{L}}\right\rangle \delta\left\langle G_{\mathrm{L}}\right\rangle / \rho_{\mathrm{L}} .
$$

Substituting $P_{\text {atm }}-\bar{P}_{\text {out }}$ into $\delta P_{\text {out }}$ yields

$$
\delta\left\langle G_{\mathrm{L}}\right\rangle=\frac{\theta \rho_{\mathrm{L}}\left(\overline{P_{\mathrm{out}}}-P_{\mathrm{atm}}\right)}{\left\langle G_{\mathrm{L}}\right\rangle},
$$

where $\theta(=1 / \Gamma)$ is a constant. The value of $\theta$ depends on the geometry of the pump, $\varepsilon$ and so on. However if we set $\theta$ about 0.02 , we can obtain a converged solution by a few iterations.

\section{APPLICATION TO AIR LIFT PUMPS FOR LIFTING LIQUIDS}

Since the two-fluid model has not been applied to air lift pumps for lifting liquid, it is uncertain if the two-fluid model and well-known correlations are of use to analyze the lifting performance under a wide range of flow condition. Hence, an examination is carried out to clarify the usefulness of the present method and well-known correlations for gas-liquid two-phase flow. For this purpose, the terms relating to the solid phase are removed from the above equations.

\subsection{Experimental Data}

Comparisons between calculated and measured $\left\langle G_{\mathrm{L}}\right\rangle$ are conducted using experimental data obtained by Saito, et al. [22] and Yoshinaga, et al.[13]. Experimental conditions are summarized in Table 1. Since important 
Table 1 Experimetnal conditons.

\begin{tabular}{c|c|c}
\hline & $\begin{array}{c}\text { Saito, et al. } \\
\text { Ref.[22] }\end{array}$ & $\begin{array}{c}\text { Yoshinaga, et al. } \\
\text { Ref.[13] }\end{array}$ \\
\hline$D[\mathrm{~m}]$ & 0.151 & $0.026,0.04$ \\
\hline$L_{\mathrm{1}}+L_{\mathrm{S}}+L_{\mathrm{D}}[\mathrm{m}]$ & 212.6 & 7.86 \\
\hline$\gamma: L_{\mathrm{S}} /\left(L_{\mathrm{S}}+L_{\mathrm{D}}\right)$ & $0.849-0.936$ & $0.6-0.8$ \\
\hline Liquid phase & water & water \\
\hline Gas phase & air & air \\
\hline$\left\langle J_{\mathrm{G}}\right\rangle_{\text {atm }}[\mathrm{m} / \mathrm{s}]$ & $0-35$ & $0-15$ \\
\hline $\begin{array}{c}\text { Structure of } \\
\text { the exit }\end{array}$ & $\begin{array}{l}\text { right-angled } \\
\text { bend and } \\
\text { horizontal pipe }\end{array}$ & - \\
\hline Temperature & $15-25^{\circ} \mathrm{C}$ & $17-23^{\circ} \mathrm{C}$ \\
\hline
\end{tabular}

parameters concerning the lifting performance such as $\left\langle J_{\mathrm{G}}\right\rangle$, the submergence ratio $\gamma\left(=L_{\mathrm{S}}\right.$ $\left./\left(L_{\mathrm{S}}+L_{\mathrm{D}}\right)\right), L_{\mathrm{I}}+L_{\mathrm{S}}+L_{\mathrm{D}}$ and $\mathrm{D}$ were varied widely, these experiments can be regarded as appropriate ones for the verification of the present method.

\subsection{Correlations}

The equation of the state for the air is given by

$$
\rho_{\mathrm{G}}=\rho_{\mathrm{Gatm}} P / P_{\mathrm{atm}},
$$

where $\rho_{\text {Gatm }}$ is the density of the air at the atmospheric pressure and the temperature $\mathrm{T}$. Since the water depth is $200 \mathrm{~m}$ at most, the compressibility of the water can be neglected. Hence $\rho_{\mathrm{L}}$ is assumed to be constant:

$$
\rho_{\mathrm{L}}=\text { water density at } T \text { and } P_{\mathrm{atm}} \text {. }
$$

Correlations required to close the model are selected from well-known correlations. As for the correlations concerning the virtual mass force, we adopt the following correlations which are implemented into the nuclear reactor safety analyses code, RELAP5/MOD1[23]:

$$
\tilde{\rho}_{\mathrm{GL}}=\rho_{\mathrm{G}}\left\langle\alpha_{\mathrm{G}}\right\rangle+\rho_{\mathrm{L}}\left\langle\alpha_{\mathrm{L}}\right\rangle,
$$

$$
\begin{aligned}
& C_{\mathrm{VGL}}=\left\{\begin{array}{c}
\left(1+2\left\langle\alpha_{G}\right\rangle\right) / 2 \\
\text { for }\left\langle\alpha_{G}\right\rangle \leqq 0.5 \\
\left\langle\alpha_{\mathrm{L}}\right\rangle\left(3-2\left\langle\alpha_{\mathrm{G}}\right\rangle\right) / 2\left\langle\alpha_{\mathrm{G}}\right\rangle \\
\text { for }\left\langle\alpha_{\mathrm{G}}\right\rangle>0.5
\end{array}\right. \\
& \kappa_{\mathrm{GL}}=1 .
\end{aligned}
$$

The distribution parameter, $C_{\mathrm{G}, \mathrm{S}}$, is estimated by Ishii's correlation[24]:

$$
C_{\mathrm{G}, \mathrm{s}}=1.2-0.2 \sqrt{\rho_{\mathrm{G}} / \rho_{\mathrm{L}}} .
$$

The drift velocity, $\bar{V}_{\mathrm{GJ}, \mathrm{S}}$ is given by the following equations [24], [25]:

$$
\begin{aligned}
& \bar{V}_{\mathrm{GJ}, \mathrm{s}}= \\
& \left\{\begin{array}{c}
\sqrt{2}\left\langle\alpha_{\mathrm{L}}\right\rangle^{-1.75}\left[\frac{g \sigma\left(\rho_{\mathrm{L}}-\rho_{\mathrm{G}}\right)}{\rho_{\mathrm{L}}{ }^{2}}\right)^{0.25}, \\
\text { for }\left\langle\alpha_{\mathrm{G}}\right\rangle \leqq 0.25, \\
0.35\left[\frac{g D\left(\rho_{\mathrm{L}}-\rho_{\mathrm{G}}\right)}{\rho_{\mathrm{L}}}\right]^{0.5}, \\
\text { for } 0.3 \leqq\left\langle\alpha_{\mathrm{G}}\right\rangle \leqq 0.8,
\end{array}\right.
\end{aligned}
$$

It has been assumed in Eq. (64) that flow pattern is a bubbly flow for $\left\langle\alpha_{\mathrm{G}}\right\rangle \leqq 0.25$, and a slug flow for $0.3 \leqq\left\langle\alpha_{\mathrm{G}}\right\rangle \leqq 0.8$. If $\left\langle\alpha_{\mathrm{G}}\right\rangle$ lies between 0.25 and $0.3, \bar{V}_{\mathrm{GJ}, \mathrm{S}}$ is calculated by an interpolation with respect to $\left\langle\alpha_{G}\right\rangle$ in order to maintain continuity of $\bar{V}_{\mathrm{GJ}, S}$. It has been pointed out that the constant, 0.35 , in the second equation of Eq. (64) is not valid for pipes whose diameter are less than $0.01 \mathrm{~m}$ or larger than $0.1 \mathrm{~m}$ [26],[27]. Hence in the analyses of Saito's experiment, the value 0.35 is replaced with 0.52 which is recommended by Hirao, et al. [27] for $\mathrm{D}>0.05 \mathrm{~m}$.

The following model [28], [29] for $(\overline{d P /}$ $\mathrm{dz})_{\mathrm{f}}$ has been widely used for air lift pump analyses: 


$$
\left(\frac{\mathrm{d} \bar{P}}{\mathrm{~d} z}\right)_{\mathrm{f}}=\frac{\lambda\left\langle G_{\mathrm{L}}\right\rangle^{2}}{2 \mathrm{D} \rho_{\mathrm{L}}}\left\langle\alpha_{\mathrm{L}}\right\rangle^{-1.75},
$$

where

$$
\lambda=\left\{\begin{array}{c}
64 / R e_{\mathrm{L}}, \\
\text { for } R e_{\mathrm{L}} \leqq 2300, \\
0.3164 / R e_{\mathrm{L}}^{0.25}, \\
\text { for } R e_{\mathrm{L}}>2300,
\end{array}\right.
$$

and

$$
R e_{\mathrm{L}}=\left\langle G_{\mathrm{L}}\right\rangle D / \mu_{\mathrm{L}} .
$$

Since direct contact between bubbles and the pipe wall is not observed so often in bubbly and slug flow regimes, the parameters, $\omega_{\mathrm{G}}$ and $\omega_{\mathrm{L}}$, in Eq. (23) are specified as follows:

$$
\omega_{\mathrm{G}}=0, \quad \omega_{\mathrm{L}}=1 \text {. }
$$

\subsection{Comparisons}

Firstly, the experiments by Yoshinaga, et al. were analyzed. They reported that the pressure drop coefficients, $\xi_{\text {in }}$ in Eq. (40), $\xi_{\mathrm{e}}$ in Eq. (42) and $\xi_{\mathrm{m}}$ in Eq. (50) were given by

$$
\zeta_{\mathrm{in}}=0.56, \quad \zeta_{\mathrm{e}}=1, \quad \zeta_{\mathrm{m}}=1 .
$$

Since no special structures were installed at the exit of the pipe, it was assumed that $\Delta P_{\text {out }}=0$. Numerical integration of Eq. (37) was conducted with the 4 th order optimized Runge-Kutta method[30]. Figure 3 shows a comparison between measured and calculated lifting performance. Effects of the submergence ratio $\gamma$, the pipe diameter $D$, and the air flow rate on a lifted liquid $\left\langle J_{\mathrm{L}}\right\rangle$ were predicted fairly well by the present method.

Then, the experiments by Saito, et al. were analyzed. The structures of the inlet and the mixing section of their pump were similar to those of Yoshinaga, et al. Hence the values of $\xi_{\text {in }}, \xi_{\mathrm{e}}$ and $\xi_{\mathrm{m}}$ were specified

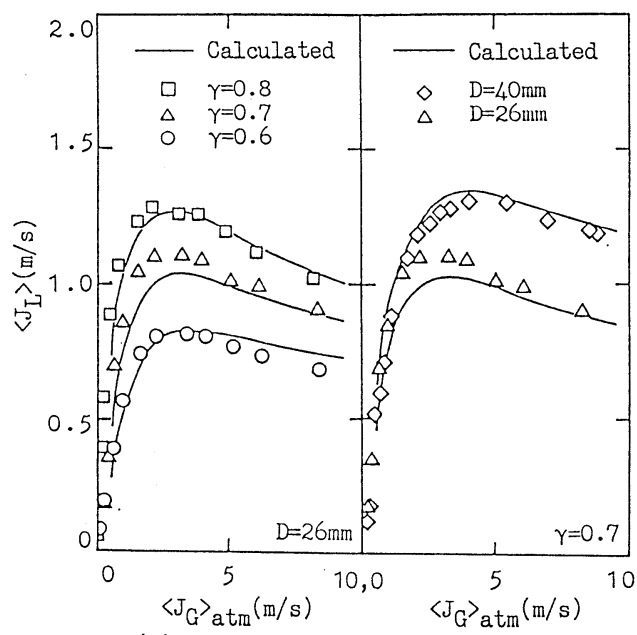

$\begin{array}{ll}\text { (a) Effect of } \gamma & \text { (b) Effect of } D\end{array}$

Fig. 3 Comparisons between measure[13] and calculated $\left\langle J_{\mathrm{L}}\right\rangle$.

by Eq. (69). On the other hand, a right-angled bend with a radius $R_{\mathrm{B}}=5 \mathrm{~m}$ and a horizontal straight pipe with a length $L_{\mathrm{B}}=2 \mathrm{~m}$ were installed at the exit of the pump as shown in Fig.1[31]. Hence $\Delta P_{\text {out }}$ consists of the singular pressure drop caused by the bend and the frictional pressure drop due to the wall of the straight pipe and the bend. The singular pressure drop due to the bend was estimated using an empirical correlation for the single phase flow in a right-angled bend. As a result, the singular pressure drop was found to be negligible. Only frictional pressure drop was therefore taken into account to evaluate $\Delta P_{\text {out }}$ as follows:

$$
\Delta P_{\text {out }}=\left(\frac{\mathrm{d} \bar{P}}{\mathrm{~d} z}\right]_{\mathrm{f}}\left(\left(\frac{\pi}{2}-1\right) R_{\mathrm{B}}+L_{\mathrm{B}}\right),
$$

where $(\overline{d P /} d z)_{\mathrm{f}}$ is calculated using Eq. (65) and $(\pi / 2-1) R_{\mathrm{B}}+L_{\mathrm{B}}$ is an additional length of the pipe. Comparisons between measured and calculated $\left\langle J_{\mathrm{L}}\right\rangle$ are shown in Fig. 4. As shown in this figure, the present method can predict $\left\langle J_{\mathrm{L}}\right\rangle$ well even if the gas flow rate, the length and the diameter of the pipe are 


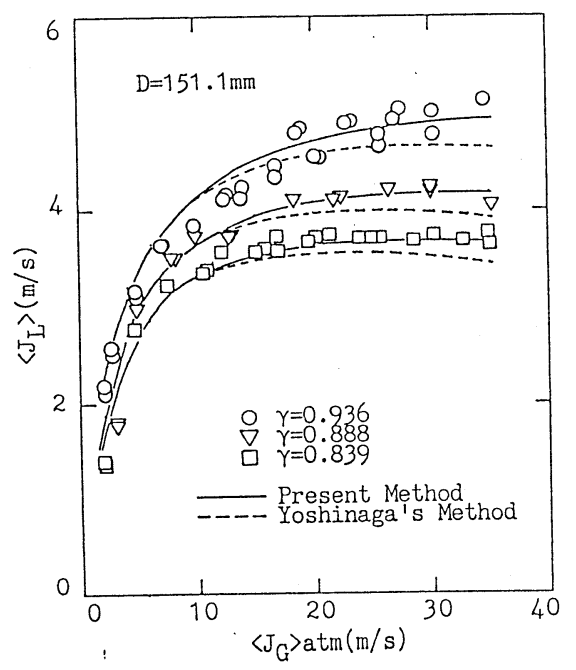

Fig. 4 Comparisons between Saito's data[22] and calculated ones.

large.

Recently, Yoshinaga et al. proposed an accurate method of air lift pump analyses based on the slip flow model. They had compared their method with other methods. As a result, they concluded that their method is more accurate than the others. Therefore a comparison between Yoshinaga's method and the present one was carried out using
Saito's data. Originally, Yoshinaga's method did not take into account the singular pressure drop at the exit of the pipe. So the singular pressure drop expressed by Eq. (70) was incorporated into Yoshinaga's method. Broken lines in Fig. 4 correspond to their method. The present method gave somewhat better results than Yoshinaga's method. However Yoshinaga's method is not so bad. Figure 5 shows an example of axial variations of flow quantities in two-phase flow region which was obtained by the present method. This figure shows that the accelerational pressure drop is not so large even though the length of the pipe is about $200 \mathrm{~m}$. If the acceleration is not so large, the slip flow model can be applied. This must be the reason why Yoshinaga's method could give a good prediction for this pump.

It was confirmed by the above comparisons that the performance of air lift pumps under a wide range of flow condition can be predicted well with the present method which is based on the multi-fluid model and the well-known constitutive equations.

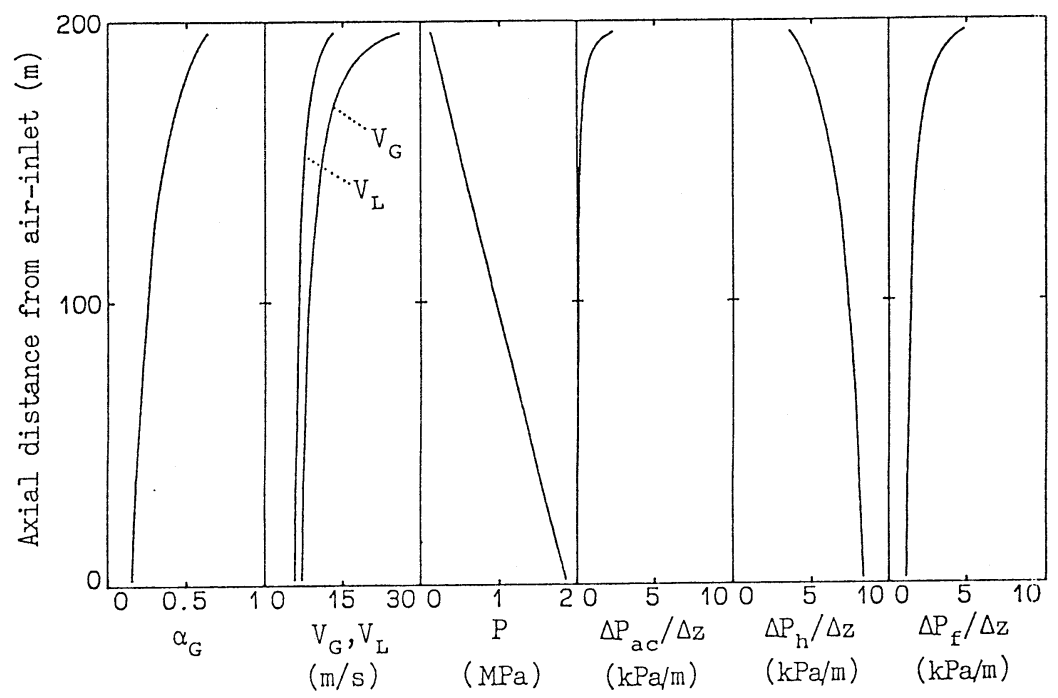

Fig. 5 Axial Variation of Flow Quatities obtained by the Present Method: $\gamma=0.936$, $J_{\text {Gatm }}=20 \mathrm{~m} / \mathrm{s}$. 


\section{APPLICATION TO AIR LIFT PUMPS FOR LIFTING SOLID PARTICLES}

Analyses of air-lift pumps for lifting solid particles were conducted based on the three-fluid model. The experiments by Yoshinaga, et al. [13] were analyzed as an example.

\subsection{Correlations for the Three-Phase Flow}

We must prepare several correlations. However there are few available correlations for the gas-liquid-solid three-phase flow. Though the authors have already proposed correlations for the interfacial drag force[17], the applicable ranges of these correlations are not consistent with the experimental ranges of Yoshinaga,et al. Hence, correlations for gas-liquid or solid-liquid two-phase flow were tentatively applied to the hypothetical gas-liquid or solid-liquid two-phase flow.

The volumetric fraction in the hypothetical two-phase flow, which is conceived by removing $\mathrm{k}$-phase from the the $\mathrm{i}, \mathrm{j}$ and $\mathrm{k}$ phases, is given by [16],[17]

$$
\left\langle\alpha_{\mathrm{n}}\right\rangle_{\mathrm{k}}=\frac{\left\langle\alpha_{\mathrm{n}}\right\rangle}{1-\left\langle\alpha_{\mathrm{k}}\right\rangle}(n=i \text { or } j) .
$$

Replacing $\left\langle\alpha_{n}\right\rangle$ in Eqs. (60)-(62) with $\left\langle\alpha_{n}\right\rangle_{, k}$ yields the following correlations for the virtual mass forces, $\left\langle M_{\mathrm{VGL}}\right\rangle$ and $\left\langle M_{\mathrm{VLS}}\right\rangle$ :

$$
\tilde{\rho}_{\mathrm{GL}}=\rho_{\mathrm{G}}\left\langle\alpha_{\mathrm{G}}\right\rangle_{\mathrm{s}}+\rho_{\mathrm{L}}\left\langle\alpha_{\mathrm{L}}\right\rangle_{\mathrm{s}, \mathrm{s}},
$$

$$
C_{\mathrm{VGL}}=\left(\begin{array}{c}
\left(1+2\left\langle\alpha_{\mathrm{G}}\right\rangle, \mathrm{s}\right) / 2, \\
\text { for }\left\langle\alpha_{\mathrm{G}}\right\rangle, \mathrm{s} \leqq 0.5, \\
\frac{\left\langle\alpha_{\mathrm{L}}\right\rangle_{\mathrm{s}}\left(3-2\left\langle\alpha_{\mathrm{G}}\right\rangle, \mathrm{s}\right)}{2\left\langle\alpha_{\mathrm{G}}\right\rangle, \mathrm{s}} \\
\text { for } \left.\left\langle\alpha_{\mathrm{G}}\right\rangle, \mathrm{s}\right\rangle 0.5,
\end{array},\right.
$$

$$
\begin{aligned}
& \kappa_{\mathrm{GL}}=1, \\
& \tilde{\rho}_{\mathrm{LS}}=\rho_{\mathrm{S}}\left\langle\alpha_{\mathrm{S}}\right\rangle_{, \mathrm{G}}+\rho_{\mathrm{L}}\left\langle\alpha_{\mathrm{L}}\right\rangle_{, \mathrm{G}},
\end{aligned}
$$

$$
C_{\mathrm{VLS}}=\left(\begin{array}{c}
\left(1+2\langle\alpha \mathrm{s}\rangle_{\mathrm{G}}\right) / 2, \\
\text { for }\left\langle\alpha_{\mathrm{S}}\right\rangle_{, \mathrm{G}} \leqq 0.5, \\
\frac{\left\langle\alpha_{\mathrm{L}}\right\rangle_{, \mathrm{G}}\left(3-2\left\langle\alpha_{\mathrm{S}}\right\rangle_{\mathrm{G}}\right)}{2\left\langle\alpha_{\mathrm{S}}\right\rangle_{\mathrm{G}}} \\
\text { for } \left.\left\langle\alpha_{\mathrm{S}}\right\rangle_{, \mathrm{G}}\right\rangle 0.5,
\end{array}\right.
$$

$$
\kappa_{\mathrm{LS}}=1 .
$$

The gas and the solid phases are dispersed in the liquid phase for bubbly and slug flow regimes. Hence they do not interact each other so often. Therefore $\left\langle M_{\mathrm{VGS}}\right\rangle$ and $\left\langle M_{\mathrm{DGS}}\right\rangle$ can be assumed as

$$
\left\langle M_{\mathrm{VGS}}\right\rangle=0, \quad\left\langle M_{\mathrm{DGS}}\right\rangle=0 .
$$

Equation (63) is adopted for the distribution parameter of the gas phase. The drift velocity of the gas phase is evaluated by replacing $\left\langle\alpha_{n}\right\rangle$ in Eq. (64) with $\left\langle\alpha_{n}\right\rangle,{ }_{k}$ :

$$
\begin{aligned}
& {\overline{V_{\mathrm{GJ}, \mathrm{S}}}}= \\
& \begin{array}{c}
\sqrt{2}\left\langle\alpha_{\mathrm{L}}\right\rangle, \mathrm{s}^{-1.75}\left(\frac{g \sigma\left(\rho_{\mathrm{L}}-\rho_{\mathrm{G}}\right)}{\rho_{\mathrm{L}}^{2}}\right)^{0.25}, \\
\text { for }\left\langle\alpha_{\mathrm{G}}\right\rangle, \mathrm{s} \leqq 0.25
\end{array} \\
& \begin{array}{l}
0.35\left[\frac{g D\left(\rho_{\mathrm{L}}-\rho_{\mathrm{G}}\right)}{\rho_{\mathrm{L}}}\right)^{0.5}, \\
\quad \text { for } 0.3 \leqq\left\langle\alpha_{\mathrm{G}}\right\rangle_{\mathrm{S}} \leqq 0.8 .
\end{array}
\end{aligned}
$$

The drift velocity of the solid phase in the hypothetical solid-liquid flow is given by [32]

$$
\bar{V}_{\mathrm{S} J, G}=-V_{\infty}\left(1-\left\langle\alpha_{\mathrm{S}}\right\rangle_{, G}\right)^{2.39},
$$

where $V_{\infty}$ is the terminal settling velocity of a single spherical particle, which can be calculated by solving the following three equations simultaneously[33]: 


$$
\begin{aligned}
V_{\infty} & =\sqrt{\frac{4 d_{\mathrm{S}}\left(\rho_{\mathrm{S}}-\rho_{\mathrm{L}}\right) g}{3 C_{\mathrm{D} \infty} \rho_{\mathrm{L}}}}, \\
C_{D \infty} & =\frac{24}{R e_{\infty}}\left(1+0.15 R e_{\infty}^{0.687}\right) \\
& +\frac{0.42}{1+42500 R e_{\infty}^{-1.16}}, \\
R e_{\infty} & =\rho_{\mathrm{L}} V_{\infty} d_{\mathrm{S}} / \mu_{\mathrm{L}} .
\end{aligned}
$$

Here $d_{\mathrm{S}}$ denotes the diameter of the solid particle. Experimental data on the distribution parameter of the solid phase in the hypothetical solid-liquid two-phase flow was deduced by using Eq. (80) and experimental data obtained by the authors [21]. For simplicity, an averaged value of these experimental data is adopted for $C_{\mathrm{S}, \mathrm{G}}$ as follows:

$$
C_{\mathrm{s}, \mathrm{G}}=1.16 \text {. }
$$

The wall frictions of each phase are estimated with Eqs. (65) $-(68)$ and $\omega_{S}=0$.

The above-mentioned correlations for the hypothetical solid-liquid two-phase flow are also applied to the calculation of the solid-liquid two-phase flow in the suction part.

\subsection{Results}

Spherical solid-particles were used in the experiments of Yoshinaga, et al. Their diameters ranged from 6 to $9.92 \mathrm{~mm}$ while their densities from 2540 to $3630 \mathrm{~kg} / \mathrm{m}^{3}$. Other experimental conditions were the same as ones shown in Table 1. Calculated $\left\langle J_{\mathrm{L}}\right\rangle$ is compared with measured one in Fig.6. Although the correlations adopted for the present calculations were tentative ones, effects of the pipe diameter, the submergence ratio and the solid flow rate on the lifting performance were predicted well. However, in order to establish a more universal and accurate method of air-lift pump analyses, it is in-

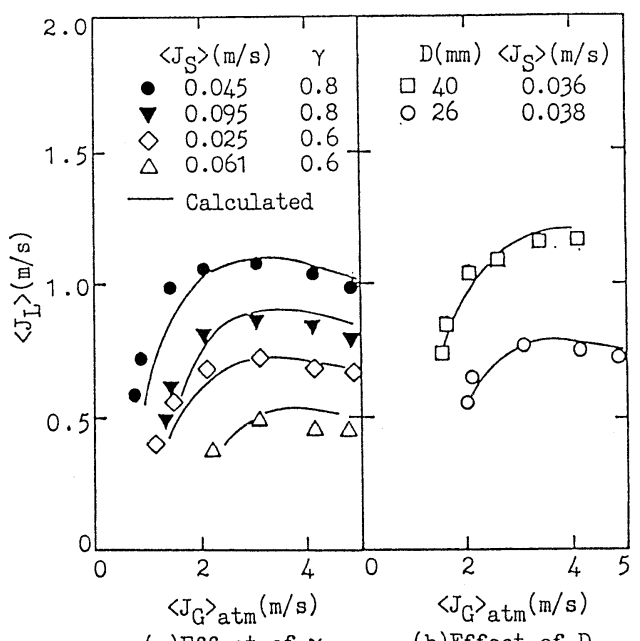

(a) Effect of $\gamma$

(b) Effect of $D$

Fig. 6 Comparisons between measured[13] and calculated $\left\langle J_{\mathrm{L}}\right\rangle$.

dispensable to develop more reliable correlations for the gas-liquid-solid three-phase flow.

\section{CONCLUSION}

For the prediction of air lift pump performance, a numerical method based on the multi-fluid model for steady gas-liquid-solid three-phase flows was proposed in the present study. This method takes into account all components of the total pressure drop in the pumps. Since it had not been clear if the multi-fluid model could be applicable to the analyses of air lift pump, air lift pumps to lift only liquid were analyzed by using wellknown correlations of the two-fluid model. It was confirmed by the comparisons between calculated and available experimental data that the present method can predict the lifting performance well under a wide range of flow condition. In other words, the validity of the present method and the adopted correlations was confirmed. Then, the analysis of an air lift pump for lifting solid particles was carried out by making use of available correlations for the two-fluid models of 
gas-liquid and solid-liquid two-phase flows.

Although the correlations used in this analysis were tentative ones, the present method could predict the lifting performance well.

\section{NOMENCLATURE}

$A$ : flow area

$\left[\mathrm{m}^{2}\right]$

$C$ : distribution parameter

$[-]$

$C_{\mathrm{v}}$ : virtual mass coefficient

$[-]$

$D$ : pipe diameter

$[\mathrm{m}]$

$d$ : diameter of a particle or bubble $[\mathrm{m}]$

$F$ : local momentum diffusion $[\mathrm{Pa} / \mathrm{m}]$

$f \quad$ : friction factor

[-]

$G$ : local mass flux

$\left[\mathrm{kg} / \mathrm{m}^{2} \mathrm{~s}\right]$

$g$ : gravity constant

$\left[\mathrm{m} / \mathrm{s}^{2}\right]$

$J$ : local volumetric flux

$\left[\mathrm{m}^{3} / \mathrm{m}^{2} \mathrm{~s}\right]$

$L \quad$ : pipe length

[m]

$M$ : local interfacial momentum transfer

$[\mathrm{Pa} / \mathrm{m}]$

$M_{\mathrm{D}}$ : local interfacial drag force $[\mathrm{Pa} / \mathrm{m}]$

$M_{\mathrm{V}}$ : local virtual mass force $[\mathrm{Pa} / \mathrm{m}]$

$P \quad:$ pressure

$[\mathrm{Pa}]$

Re : Reynolds number

$T$ : temperature

$V$ : local velocity

$V_{\mathrm{nJ}}:$ drift velocity of $\mathrm{n}$-phase

$[\mathrm{m} / \mathrm{s}]$

$z \quad$ : axial coordinate

[m]

\section{Greek letters}

$\alpha \quad$ : local volumetric fraction

$[-]$

$\gamma$ : submergence ratio

$[-]$

$\zeta$ : singular pressure drop coefficient $[-]$

$\lambda$ : friction factor

$[-]$

$\mu \quad$ : viscosity

$[\mathrm{kg} / \mathrm{ms}]$

$\rho:$ density

$\left[\mathrm{kg} / \mathrm{m}^{3}\right]$

$\sigma$ : surface tension

$[\mathrm{N} / \mathrm{m}]$

\section{Subscripts}

atm: a value at the atmospheric pressure

f : friction

$\mathrm{G}$ : gas phase
L : liquid phase

$\mathrm{S}$ : solid phase

, $\mathrm{k}$ : index for a removed phase

\section{REFERENCES}

[1] D.J.Nicklin: The Air-Lift Pump, Theory and Optimization, Trans. Instn. Chem. Engrs. ,41,1963, (1963).

[2] A.H.Stenning, C.B.Martin: An Analytical and Experimental Study of Air-Lift Pump Performance, Trans. ASME,106, (1968).

[ 3 ] I.Todoroki., Y.Sato, T.Honda : Performance of Air-Lift Pump, Bull. JSME, 38-312, 2085(1973).

[4] T.Kawashima, et al. : Hydraulic Conveying Solid Particles by Air-Lift, J. of the Mining and Metallurgical Inst. of Japan, 91-1054,765, (1975), in Japanese.

[5] M.Weber, M.Y.Dedegil : Transport of Solids according to the Air-Lift Principle, Proc. 4th Int. Conf. on the Hydraulic Transport of Solids in Pipes, Alberta, Canada, H1.1(1976).

[6] M.Weber : Vertical Hydraulic Conveying of Solids by Air-Lift, J. of Pipelines, 3, 137(1982).

[ 7 ] M.Y.Dedegil : Neuere Untersuchungen zum Lufthebeverfahren, Verfahrenstechnik, 16-4, 229, (1982).

[8 ] N.N.Clark, R.J.Dabolt: A General Design Equation for Air Lift Pumps Operating in Slug Flow, AIChE J., 32-1, 56, (1986).

[9] B.P.A.Grandjean, et al. : Study of an Air-Lift System, Part 1, Hydrodynamics of the Atara Piston Bubble Cannon Mixer, Canadian J. of Chem.Engrs. ,65,430, (1987).

[10] T.Saito, et al. : Simulation of Steady State Performance of Lifting Manganese Nodules by Air Lift Pumps, Prepr. Spring Mtg. of the Mining and Metallurgical Inst. of Japan, 337, (1987), in Japanese.

[11] T.Sakaguchi, et al. : Numerical Simulation 
of Steady State Gas-Liquid-Solid ThreePhase Flow in Air-Lift Pumps, Prepr. JSME, 890-50, 255, (1989), in Japanese.

[12] N.Hatakeyama ,T.Masuyama : Numerical Simulation for Lifting Characteristics of Water with Large Scale Air-Lift Pump, J. of the Mining and Materials Processing Inst. of Japan., 105-14, 1051, (1989), in Japanese.

[13] T.Yoshinaga, Y.Sato, M.Sadatomi : Characteristics of Air-Lift Pump for Conveying Solid Particles, Japanese J. of Multiphase Flow,4-3,174, (1990), in Japanese.

[14] T.Saito, E.D.Hughes, M.W.Carbon : MultiFluid Modelling of Annular Two-Phase Flow, Nucl. Eng. Des., 50, 255,(1978).

[15] M.Ishii : Thermo-Fluid Dynamics Theory of Two-Phase Flow, Eyrolles, (1975).

[16] A.Tomiyama, H.Minagawa, T.Sakaguchi : Derivation of Constitutive Equations for Interfacial Momentum Transfer Required for the Analyses of Gas-Liquid-Solid Three-Phase Flow with One-Dimensional Three-Fluid Model, Trans. JSME, 57-536, 1239, (1991), in Japanese.

[17] A.Tomiyama,et al. : Constitutive Equations for Interfacial Momentum Transfer in Three-Phase Flow and Application of them to Gas-Liquid-Solid Three-Phase Bubbly Flow, Proc. ASME-JSME Thermal Eng. Joint Conf. 1991, 2,101,(1991).

[18] D. Drew, L. Cheng, R.T.Lahey, Jr. : The Analyses of Virtual Mass Effects in Two-Phase Flow, ,Int. J. Multiphase Flow, 5-4,233, (1979).

[19] T.Sakaguchi, et al. : Examination of Constitutive Equations Required for the Analyses of Solid-Liquid Two-Phase Flow in Vertical Pipes with the Two-Fluid Model, Trans.JSME, 56-525,1368, (1990), in Japanese.

[20] T.Sakaguchi,et al. : Study on Characteristics of Gas-Liquid-Solid Three-Phase Bubbly Flow (1)Characteristics of Volumetric Fractions of Each Phase, Prepr.JSME, 904-2, 175, (1990), in Japanese.

[21] T.Sakaguchi, et al. : Estimation of Volumetric Fraction of Each Phase in Gas-LiquidSolid Three-Phase Flow, 1987 ASME-JSME Thermal Engng. Joint Conf. Honolulu, Hawaii, 373, (1987).

[22] T.Saito, et al. : Lifting Characteristics of Manganese Nodules by Air Lift Pump under Steady State Conditions; (1st Rep.) Fundamental Results of $200 \mathrm{~m}$ Test Plant, Mining and Safety, 32-10, 540,(1986), in Japanese.

[23] V.H.Ransom, et al. : RELAP5/MOD1 Code Manual, Vol.1; System Model and Numerical Methods, NUREG/CR-1826, EGG-070, (1982).

[24] M.Ishii : One-Dimensional Drift-Flux Model and Constitutive Equations for Relative Motion between Phases in Various Flow Regimes, ANL-77-47, (1977).

[25] N.Zuber, J.A.Findlay : Average Volumetric Concentration in Two-Phase Flow System, Trans. ASME, 87-4, 453, (1965).

[26] E.T.White, R.H.Beardmore : The Velocity of Rise of Single Cylindrical Air Bubbles through Liquids contained in Vertical Tubes, Chemical Engng. Science, 17, 351 (1962).

[27] Y.Hirao, et al. : Experimental Study on Drift Flux Correlation Formulas for Two-Phase Flow in Large Diameter Tubes, 2nd Int. Topical Meeting on Nucl. Power Plant Thermal Hydraulic and Operation, Tokyo, 1-88, (1986).

[28] B.L.Richardson : Some Problems in Horizontal Two-Phase Two-Component Flow, ANL-5949, (1958).

[29] I.Katsuhara: Influence of Wall Roughness on Two-Phase Flow Frictional Pressure 
Drops, Trans. JSME, $24-148,1050$, (1958), in Japanese.

[30] H.Togawa : Numerical methods for differential equations, Ohm Co. Ltd., 37, (1973), in Japanese.

[31] T.Saito : private communication.
[32] J.F.Richardson,W.N.Zaki : Sedimentation and Fluidization, Part I, Trans.Instn. Chem. Eng., 32, 35,(1954).

[33] R.Clift, W.H Gauvin: The motion of Particles in Turbulent Gas Streams, Proc. Chemeca ' 70, 1, 14, (1970). 